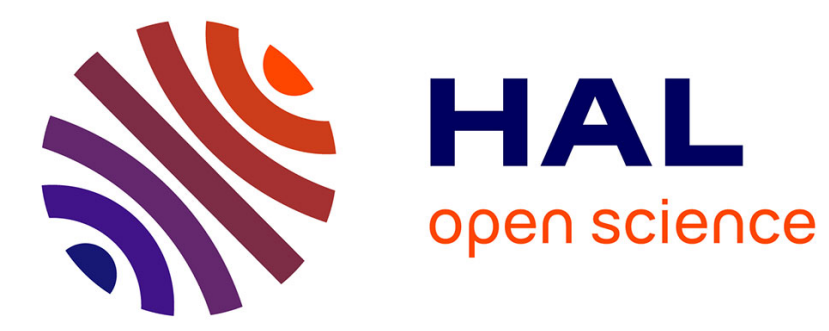

\title{
Effect of a hyperbaric environment (diving conditions) on adhesive restorations: an in vitro study
}

C. Mocquot, A Cabrera, P. Colon, J. Bosco, B. Grosgogeat, N. Pradelle-Plasse

\section{To cite this version:}

C. Mocquot, A Cabrera, P. Colon, J. Bosco, B. Grosgogeat, et al.. Effect of a hyperbaric environment (diving conditions) on adhesive restorations: an in vitro study. British Dental Journal, 2017, 223 (5), pp.347-351. 10.1038/sj.bdj.2017.764 . hal-02445683

\section{HAL Id: hal-02445683 \\ https://hal.science/hal-02445683}

Submitted on 24 Jan 2020

HAL is a multi-disciplinary open access archive for the deposit and dissemination of scientific research documents, whether they are published or not. The documents may come from teaching and research institutions in France or abroad, or from public or private research centers.
L'archive ouverte pluridisciplinaire HAL, est destinée au dépôt et à la diffusion de documents scientifiques de niveau recherche, publiés ou non, émanant des établissements d'enseignement et de recherche français ou étrangers, des laboratoires publics ou privés. 


\title{
Effect of a hyperbaric environment (diving conditions) on
}

\section{adhesive restorations: An in-vitro study}

\author{
C. Mocquot, A. Cabrera, P. Colon, J. Bosco, B. Grosgogeat \& N. Pradelle-Plasse
}

\begin{abstract}
Objectives: No recent study has addressed the effect of diving conditions (pressure increase) on adhesive restorations. We evaluated the impact of a simulated hyperbaric environment on microleakage of the dentine-composite resin interface. The ultimate aim was to propose recommendations for restorative dentistry for patients who are divers to limit barodontalgia (dental pain caused by pressure variations of the environment) and may lead to dangerous sequelae.

Methods: We bonded 20 dentine disks by using an adhesive system (Scothbond Universal ${ }^{\circledR}$ ) to 10 intact composite cylinders and 10 composite cylinders with porosity (Ceram X mono ${ }^{\circledR}$ ). For each group, the samples were divided into two subgroups, one submitted to a simulated hyperbaric environment and the other to an ambient environment. All samples were immersed in a silver nitrate solution to evaluate microleakage at the interface after analysis with a camera.

Results: Dye percolation for groups in the hyperbaric environment was greater than groups in ambient environment. For each subgroup, dye percolation was greater for samples with than without porosity. Conclusions: High percolation percentages demonstrate that our simulated hyperbaric condition led to loss of sealing at the dentine-composite resin interface, especially with porous composites.

Clinical significance: Respect of the protocol and the quality of condensation for adhesive restorations are important in all clinical situations, especially for patients who are divers. A more interventionist approach must be adopted with these patients.
\end{abstract}




\section{Introduction}

The number of Professional Association of Diving Instructors (PADI) certifications has increased from 17 million in 2008 to 23 million in $2015^{1}$. Consequently, dentists are increasingly seeing patients with dental pain after an underwater dive (barodontalgia) but also patients wondering about restoration treatment before diving.

Barodontalgia is defined as dental pain caused by pressure variations of the environment. This pain was previously called aerodontalgia because it concerned essentially pilots in a hypobaric environment ("aero" meaning air in Greek). After the Second World War, many studies investigated this phenomenon ${ }^{2}$. In 1965, Shiller studied dental pain under hyperbaric conditions ${ }^{3}$ : the phenomena involved in dental pain in hypobaric and hyperbaric conditions were similar. Therefore, the term barodontalgia resulted from this study, "baro" referring to the variations of pressure 45.

Barodontalgia may be associated with dental fractures or restoration fractures but also to lack of retention of fillings, called dental barotrauma. The variations in volume involved in barotrauma are explained by the law of Boyle-Mariotte: at constant temperature, the volume of a gas is inversely proportional to its pressure (pressure $\mathrm{x}$ volume $=$ constant $)^{6}$. Dental pain can also occur without a diving barotrauma. It is an acute expression of a pre-existing clinical pathology (reversible pulpitis, irreversible pulpitis, necrosis or periapical disease). For divers, the ultimate consequence of extreme barodontalgia can be an oversight of safety rules, in particular respecting decompression stops, which can lead to death.

Most studies of barodontalgia were published before 1990, so articles and case reports do not correspond to the current treatment protocol for restorative dentistry ${ }^{78910}$.

The aim of our study was to evaluate whether restorative dentistry protocols should be refined for patients who are divers. Indeed, Ranna et al. reported in study of 100 recreational divers, that among the divers who experienced dental symptoms, $54 \%$ had a tooth cavity or a previous filling ${ }^{11}$. We performed also an experimental in vitro study to measure the impact of a pressure increase on 
microleakage at a dentine-composite resin interface and we examined restorations with a perfect marginal adaptation to dental structures and composite restorations with porosity.

\section{Materials and methods}

\section{1) Samples}

We collected 20 third-molars extracted for orthodontic reasons from young adult patients. All teeth were obtained with the patients' informed consent and with approval of our local ethics committee for human studies (Art R1211 CSP). Immediately after collection, teeth were gently cleaned with tap water and kept in a $1 \%$ chloramine solution at $4^{\circ} \mathrm{C}$ for up to 1 month.

\section{2) Materials}

The materials used were for the adhesive protocol Scotchbond Universal Etchant ${ }^{\circledR}$ and Scotchbond Universal Adhesive ${ }^{\circledR}$ (3M ESPE Dental Products, St. Paul, Minnesota, USA, batch 70201139014) and Ceram X mono ${ }^{\circledR}$ (Dentsply, Milford, Delaware, USA, batch 141000804) for the composite resin. The polymerization involved use of light Astralis ${ }^{\circledR}{ }^{\circledR}$ (Ivoclar Vivadent, Schaan, Liechtenstein) for all samples. The irradiance tested with a curing radiometer was $750 \mathrm{~mW} / \mathrm{cm} 2$, which was consistent during all procedures.

\section{3)Microleakage method}

Dentine disk preparation $(n=20)$

Each tooth was embedded in a cold curing epoxy resin, ClaroCit Kit ${ }^{\circledR}$ (Stuers, Westlake, Cleveland, USA). Then samples were cut horizontally twice with use of a diamond circular blade under constant irrigation to obtain a disk located at the one-third median of the dentine. Then the sectioned surfaces were polished with abrasive paper disks of decreasing 500 and 1200 coarseness at $3.000 \mathrm{rpm}$ under water irrigation to obtain standardized surfaces. The last granulometry corresponds to the yellow ring of a diamond bur. Between each polishing sequence, the disks were left 10 minutes in an ultrasonic bath.

Dentine disks were $10 \mathrm{~mm}$ in diameter and $3 \mathrm{~mm}$ high 
Composite resin disk preparation

Composite Ceram X mono ${ }^{\circledR}$ cylinders were created by means of nylon slices $8 \mathrm{~mm}$ in internal diameter and $2 \mathrm{~mm}$ high to produced two types of cylinders: 10 uniform cylinders (Fig. 1) and 10 cylinders in which a polyester ball (2 $\mathrm{mm} \varnothing)$ was placed before polymerization to simulate porosity (Fig. 1). Each sample was polymerized for $20 \mathrm{sec}$.

\section{Bonding of dentine disks and composite resin disks}

To create an adhesive interface, dentine disks were bonded to composite cylinders ( $\mathrm{n}=10$ with porosity: group A; n=10 without porosity : group B) by using an adhesive system (Scotchbond Universal $^{\circledR}$ ) according to the manufacturer's instructions as a total etch protocol. A phosphoric acid etching gel (about 35\%), Scotchbond Universal Etchant ${ }^{\circledR}$, was applied to dentine for 15 sec, then rinsed thoroughly with water and dried with water-free and oil-free air without overdrying. Scotchbond Universal Adhesive was applied with the disposable applicator to the entire tooth structure and rubbed for $20 \mathrm{sec}$. If necessary, the disposable applicator was re-wet during treatment. Then a gentle stream of air was directed over the liquid for about $5 \mathrm{sec}$ until it no longer moved and the solvent had evaporated completely. The composite disk was placed on the dentine disk, and the adhesive was polymerized with a commonly used curing light for $10 \mathrm{sec}$. The periphery of the cylinder obtained was polished with use of a Diamond flame bur red ring until the alignment of both dentin disks and composite resin disks (diameter $8 \mathrm{~mm}$ ).

\section{Group distribution function of experimental environment}

Groups A and B were divided into 2 groups of 5 samples treated under hyperbaric conditions (groups A1 and B1) or ambient pressure (groups A2 and B2) (table 1).

The hyperbaric condition involved placing samples in a cylinder that simulated a dive (Fig. 2). The cylinder was connected to a 12-litre dive bottle by means of a pipe and a manual valve for controlling 
the pressure inside the cylinder. The samples were subjected to 6 cycles of $30 \mathrm{~min}$ each to a pressure between 5.5 and 6 bars, equivalent to a depth of 45 to $50 \mathrm{~m}$ underwater.

\section{Dye protocol}

The external surfaces of each sample were completely coated with two layers of nail varnish, with a 1$\mathrm{mm}$ wide margin around the interface restoration left free of varnish. Specimens were immersed in a 50 weight (wt) \% silver nitrate aqueous solution for 2 hours in total darkness, then placed in distilled water and exposed to fluorescent light for $12 \mathrm{hr}$. They were immersed in photodeveloping solution for 2 hours (Kodak SA), then rinsed thoroughly in running water and immersed in acetone to dissolve the nail varnish. Each was embedded in a cold curing epoxy resin (ClaroCit $\mathrm{Kit}^{{ }^{\circledR}}$ ).

By using a diamond blade circular disk (Accutom ${ }^{\circledR}$, Struers) at a disc speed of $550 \mathrm{rpm}$ and with a cutting lubricant (Struers), each sample tooth was sectioned vertically into three sections, thereby obtaining six interfaces.

The dye penetration was measured at the dentine-composite resin interface by using a binocular loop connected to a camera and analyzed by using Leica software (Leica Microsystems Imaging, Cambridge, UK). The percentage microleakage was defined as the measured length of the dye penetration divided by the measured length of the interface. The mean percentage microleakage was the mean of 5 specimens $(5 \times 3 * 6=90$ interfaces $)$ for each group investigated.

\section{Statistical analysis}

Data were analyzed by one-way ANOVA with the Turkey test. Groups were compared by MannWhitney $\mathrm{U}$ test. $\mathrm{P}<0.05$ was considered statistically significant.

\section{Results}

The results are presented on the table 2 and represented in a graph on table 3. 
The percentage penetration was greater for samples with than without porosity subjected to a hyperbaric condition (45\% Fig. 3 vs $37.9 \%$;) and to ambient pressure (29.8\% Fig. 4 vs 29.4\%;). Significant differences were found between Group A1 (submitted to hyperbaric conditions and presenting a porosity) and the two groups left at ambient pressure.

\section{Discussion}

Here we addressed the effect of diving conditions (pressure increase) on adhesive restorationsAt the pressure used in this experiment, equivalent to a depth of 45 to $50 \mathrm{~m}$ underwater, only experimental divers (with certification PADI TEChnical 45 and 50) or professional divers (military or speleologist) can dive but not the recreational divers.

evaluated the impact of a simulated hyperbaric environment on microleakage of the dentinecomposite resin interface. We aimed to evaluate whether restorative dentistry protocols should be refined for patients who are divers.

Highest percolation's in groups A.1 and B.1 respectively, compared to groups A.2 and B.2 show that a simulated hyperbaric condition leads to a loss of sealing at the interface. This highlights the importance of the adhesive selection and the respect of the adhesive protocol. For divers with adhesive restorations or planning to undergo such restorations, etch-and-rinse adhesive systems or self-etch systems with a preliminary enamel etching may be preferred to limit enamel penetration ${ }^{1214}$.

The greater dye penetration into the group A.1 with porosity compared to the group B.1 without porosity shows that a defect in the restoration will promote the microleakage between the inside and the outside of the interface. To limit this situation, a perfect marginal adaptation must be achieved between the restorative material and dental tissues. The use of flow composite ${ }^{15}$, instruments generating vibrations on composite ${ }^{16}$ or preheating composite ${ }^{17}$ could help limit the presence of air bubbles. Respecting the protocol and the quality of condensation are important in all situations, but especially for patients who are divers. This explanation is supported in a study by Ranna et al. In this study, more than half of the teeth affected by pain were molars ${ }^{11}$. Molars are the teeth most susceptible to decay and most frequently restored ${ }^{17}$. 
Calcium silicate-based materials (Biodentine ${ }^{\circledR}$, Pro Root MTA ${ }^{\circledR}$ etc.) for indirect pulp capping may ensure good restoration (given that direct pulp capping is not recommended for patients who are divers) but such materials are porous during the initial crystallization phase, and perhaps patients should wait to dive until after the end of the reaction so that the material completely matures ${ }^{181920 .}$

Also, current techniques for treating deep carious lesions may not be appropriate for patients who are divers. Such techniques consist of a selective removal of carious tissue, localized in the restoration margins, which leaves the cavity bottom in the affected or infected dentin. These tissues have a porous demineralized and deproteinized supporting structure with low mechanical properties. Moreover, the adhesion properties of this tissue are lacking as compared with sound dentine, and bond durability and strength are lower 2122 .

\section{Recommendations in restorative dentistry}

During an appointment, any doubt concerning the leakage of a restoration must involve reintervention. For patients who are divers, many older publications (before 1990) recommended establishing a bottom for the cavity with zinc-oxide eugenol under the amalgam filling ${ }^{23}$. The available materials require consideration of their mechanical properties, porous character and thixotropy (marginal adaptation) before their implementation in patients who are divers.

The Glass Ionomer Cement has thermal and electrical insulation, spontaneously adheres to dental tissue by reaction of chelation, compensates the composite contraction and ensures good adhesion with calcified tissues. These properties may help prevent barodontalgia ${ }^{24}$. However, Glass Ionomer Cement are sensible to desiccation ${ }^{25}$. In diving, the oral environment is exposed to dry air from the regulator. For prevent this desiccation of Glass Ionomer Cement, a surface treatment can be applied. Simmons et al, have showed that a surface treatment with $5 \% \mathrm{NaF}$ improved antimicrobial and strength properties of desiccated glass ionomer cement ${ }^{26}$. Consequently, in order to limit this problem and as this material as weak mechanical properties, we recommended to use it as dentine substitute. 
The use of a calcium hydroxide cavity liner must be limited. Indeed, due to the poor adherence and low sealing ability of a calcium hydroxide, glass Ionomer Cement, tricalcium silicate cement or composite resin are more appropriate for indirect pulp capping or liner 2728 .

For direct restorations, adhesive restorations seems to be preferred as amalgam does not adhere to dentine or enamel. But we cannot advocate amalgam restorations or composites for patients who are divers, because any studies compare microleakage in hyperbaric condition on interface dentine/amalgam versus dentine/composite. In ambient pressure, the results of studies are contradictory $^{2930}$. For divers patients, using an adhesively bonding amalgam seems interesting to increase the sealing. However, it has not been highlighted an additional benefit of adhesively bonding amalgam in compare with non-bonded amalgam ${ }^{31}$.

Indirect restorations for wide and deep cavities for patients who are divers are recommended. Indeed, the risk of defects increases with the volume of the cavity ${ }^{32}$. For prevent microleakage at the outer margins it seems recommended to apply glycerine gel to the surface of bonding composite resin during polymerization for increase marginal adaptation, ${ }^{33}$.

\section{Conclusions}

During the examination for dental restoration, dentists should investigate their patients' activities, to estimate whether the activities might affect the orofacial structures. Similarly, patients who are divers should inform their dentists about their activities/hobbies so as to prevent barodontalgia. The consequences of restorations during diving that can cause the pain and the loss of a tooth fragment or restoration are very dangerous, especially when patients are isolated during an activity. Therefore, a more interventionist approach is needed to treat dental diseases in patients who are divers.

\section{Conflict of interest: none}

\section{Funding}

This research did not receive any specific grant from funding agencies in the public, commercial, or not-for-profit sectors 


\section{References}

1 PADI. Dossier de presse - PADI EUROPE. www.padi.com.

2 Sognnaes R. Further studies of aviation dentistry. Acta Odontol Scandinava 1946; 7: 165173.

3 Shiller WR. Aerodontalgia under hyperbaric conditions. An analysis of forty-five case histories. Oral Surg Oral Med Oral Pathol 1965; 20: 694-697.

4 Hodges FR. Barodontalgia at 12,000 feet. J Am Dent Assoc 1978; 97: 66-68.

5 Rottman K. Barodontalgia: a dental consideration for the SCUBA diving patient. Quintessence Int Dent Dig 1981; 12: 979-982.

6 Hecht E. Physique. De Boeck. Bruxelles, 1999.

7 Ferjentsik E, Aker F. Barodontalgia: a system of classification. Mil Med 1982; 147: 299, 303-304.

8 Calder IM, Ramsey JD. Ondontecrexis--the effects of rapid decompression on restored teeth. J Dent 1983; 11: 318-323.

9 Senia ES, Cunningham KW, Marx RE. The diagnostic dilemma of barodontalgia. Report of two cases. Oral Surg Oral Med Oral Pathol 1985; 60: 212-217.

10 Goethe WH, Bäter H, Laban C. Barodontalgia and barotrauma in the human teeth: findings in navy divers, frogmen, and submariners of the Federal Republic of Germany. Mil Med 1989; 154: 491-495.

11 Ranna V, Malmstrom H, Yunker M, Feng C, Gajendra S. Prevalence of dental problems in recreational SCUBA divers: a pilot survey. Br Dent J 2016; 221: 577-581.

12 Chuang S, Chang L, Chang C, Yaman P, Liu J. Influence of enamel wetness on composite restorations using various dentine bonding agents: part II-effects on shear bond strength. J Dent 2006; 34: 352-361.

13 Van Meerbeek B, Peumans M, Poitevin A et al. Relationship between bond-strength tests and clinical outcomes. Dent Mater 2010; 26: 100-121.

14 Dupas C, Gaudin A, Perrin D, Marion D. Etanchéité des obturations coronaires. EMC Elsevier Masson SAS Paris Odontol. 2008; : 1-10, 23-63-NaN-10.

15 Orlowski M, Tarczydlo B, Chalas R. Evaluation of marginal integrity of four bulk-fill dental composite materials: in vitro study. ScientificWorldJournal 2015; 1155/2015/701262.

16 Dickson P, Vandewalle K, Lien W, Wajdowicz M, Santos M. Effects of preheating on the properties of silorane- and methacrylate-based composites. Gen Dent 2014; 62: 12-19.

17 Masood M, Masood Y, Newton JT. The clustering effects of surfaces within the tooth and teeth within individuals. J Dent Res 2015; 94: 281-288. 
18 Malkondu Ö, Karapinar Kazandag M, Kazazoglü E. A review on biodentine, a contemporary dentine replacement and repair material. BioMed Res Int 2014; ID 160951.

19 Villat C, Tran X, Pradelle-Plasse N. Impedance methodology: A new way to characterize the setting reaction of dental cements. Dent Mater 2010; 26: 1127-1132.

20 Camilleri J, Gregh L, Galea K. Porosity and root dentine to material interface assessment of calcium silicate-based root-end filling materials. Clin Oral Investig 2014; 18: 1437-1446.

21 Pinna R, Maioli M, Eramo S, Mura I, Milia E. Carious affected dentine: its behaviour in adhesive bonding. Aust Dent J 2015; 60: 276-293.

22 Schwendicke F, Dörfer CE, Paris S. Incomplete Caries Removal. A systematic Review and Meta-analysis. J Dent Res 2013; 92: 306-314.

23 Chenevee H. L'odontalgie pneumatogénique des plongeurs. Rev Fr Odonto-Stomatol 1958; : 1377-1384.

24 Davidson C. Glass ionomer cement, an intelligent material. Bull Group Int Rech Sci Stomatol Odontol 1998; 40: 38-42.

25 Wilson AD, Paddon JM. Dimensional changes occurring in a glass-ionomer cement. Am J Dent 1993; 6: 280-282.

26 Simmons JO, Meyers EJ, Lien W, Banfield RL, Roberts HW, Vandewalle KS. Effect of surface treatments on the mechanical properties and antimicrobial activity of desiccated glass ionomers. Dent Mater Off Publ Acad Dent Mater 2016; 32: 1343-1351.

27 Murray PE, Hafez AA, Smith AJ, Cox CF. Bacterial microleakage and pulp inflammation associated with various restorative materials. Dent Mater Off Publ Acad Dent Mater 2002; 18: $470-478$.

28 Schuurs AH, Gruythuysen RJ, Wesselink PR. Pulp capping with adhesive resin-based composite vs. calcium hydroxide: a review. Endod Dent Traumatol 2000; 16: 240-250.

29 Alptekin T, Ozer F, Unlu N, Cobanoglu N, Blatz MB. In vivo and in vitro evaluations of microleakage around Class I amalgam and composite restorations. Oper Dent 2010; 35: 641-648.

30 Hersek N, Canay S, Akça K, Ciftçi Y. Comparison of microleakage properties of three different filling materials. An autoradiographic study. J Oral Rehabil 2002; 29: 1212-1217.

31 Agnihotry A, Fedorowicz Z, Nasser M. Adhesively bonded versus non-bonded amalgam restorations for dental caries. Cochrane Database Syst Rev 2016; 3: CD007517.

32 TÜRK AG, SABUNCU M, ÜNAL S, ÖNAL B, ULUSOY M. Comparison of the marginal adaptation of direct and indirect composite inlay restorations with optical coherence tomography. J Appl Oral Sci 2016; 24: 383-390.

33 Bergmann P, Noack MJ, Roulet JF. Marginal adaptation with glass-ceramic inlays adhesively luted with glycerine gel. Quintessence Int Berl Ger 1985 1991; 22: 739-744. 


\section{Legends of figures:}

Figure 1. Composite resin samples without (left) and with (right) porosity

Figure 2. Hyperbaric simulation apparatus

Figure 3. Example of dentin - composite resin interface of sample restored with composite presenting a porosity subjected to a hyperbaric environment (Group A1)

Figure 4. Example of dentin - composite resin interface of sample restored with composite presenting a porosity subjected to an ambient-pressure environment (Group A2)

\section{Legends of tables:}

Table 1. Distribution of samples

Table 2. Percentage of dye penetration

Table 3. Percentage of dye penetration (Mean data) - Graph

Table 1: Distribution of samples

\begin{tabular}{|c|c|c|}
\hline SAMPLES & HYPERBARIC CONDITION & AMBIENT PRESSURE \\
\hline WITH POROSITY & GROUP A.1 $(n=5)$ & GROUP A.2 $(n=5)$ \\
\hline WITHOUT POROSITY & GROUP B.1 $(n=5)$ & GROUP B.2 $(n=5)$ \\
\hline
\end{tabular}


Table 2: Percentage of dye penetration

\begin{tabular}{|c|c|c|c|c|}
\hline Groups & $\begin{array}{c}\text { Group A1 } \\
\text { HC. P. }\end{array}$ & $\begin{array}{c}\text { Group B1 } \\
\text { HC. WP. }\end{array}$ & $\begin{array}{c}\text { Group A2 } \\
\text { AP. P. }\end{array}$ & $\begin{array}{c}\text { Group B2 } \\
\text { AP. WP. }\end{array}$ \\
\hline \% of percolation & $45(4,5)^{\mathrm{a}, \mathrm{b}}$ & $37,9(5,3)$ & $29,8(8,83)^{\mathrm{a}}$ & $29,4(4,96)^{\mathrm{b}}$ \\
\hline
\end{tabular}

(HC : Hyperbaric condition, AP: Ambient pressure, P : porosity, WP: without porosity) 0 : standard deviation

Statistic analysis: same letters represented examples with statistical differences $p<0.05$ 
Table 3: Percentage of dye penetration (Mean data)

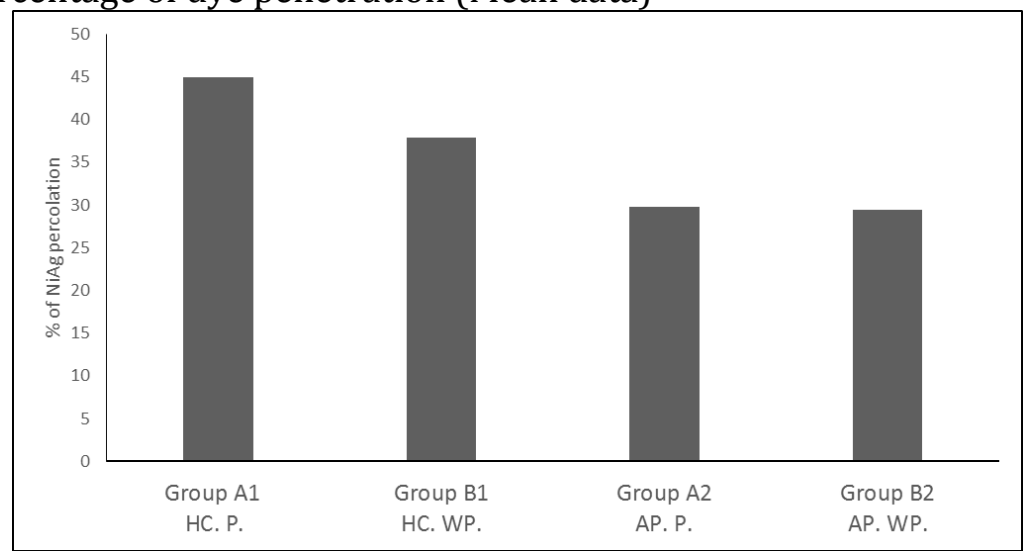

(HC : Hyperbaric condition, AP: Ambient pressure, P: porosity, WP: without porosity) 